Authors' accepted manuscript.

Article published in Metals and Materials International, vol. 27, pages 4307-4321 (2021)

The final published version is available at https://doi.org/10.1007/s12540-020-00855-x

Effect of Double Hit Hot Deformation on the Evolution of Dynamically Transformed Ferrite

\author{
K. Chadha ${ }^{1}$. C. Aranas Jr. ${ }^{2} \cdot$ M. Jahazi ${ }^{3}$
}

Received: 8 July 2020 / Accepted: 11 August 2020

(c) The Korean Institute of Metals and Materials 2020 


\title{
Effect of double hit hot deformation on the evolution of dynamically transformed ferrite
}

\author{
K. Chadha ${ }^{*}$, C. Jr. Aranas ${ }^{2}$, M. Jahazi ${ }^{3}$ \\ ${ }^{1}$ Planetary and Space Science Centre, University of New Brunswick \\ Fredericton, New Brunswick E3B 5A3, Canada \\ ${ }^{2}$ Department of Mechanical Engineering, University of New Brunswick \\ Fredericton, New Brunswick E3B 5A3, Canada \\ ${ }^{3}$ Department of Mechanical Engineering, École de technologie supérieure (ÉTS), \\ 1100 Notre Dame Street West, Montréal, Québec H3C 1K3, Canada
}

*Corresponding Author: kchadha@unb.ca

\begin{abstract}
Double-hit hot compression tests were carried on medium-carbon low-alloy steels using Gleeble $3800^{\circledR}$ thermomechanical simulator. The experiments were performed at strain rates of 0.25 and $0.5 \mathrm{~s}^{-1}$ and temperatures of 1150 and $1200{ }^{\circ} \mathrm{C}$ with interpass times of 5,15 , and $25 \mathrm{~s}$. The onset of critical stresses for dynamic transformation (DT) for both first and second hit were detected using the double-differentiation method. It was found that the critical stress for DT increased with a decrease in temperature and an increase in strain rate. The presence of dynamically transformed ferrite was observed and quantified using electron-backscatter diffraction (EBSD), Kernal Average Misorientation (KAM), and grain boundary maps. Then, a thermodynamic analysis was carried out using JmatPro software. A method of determining the change in Gibbs energy during DT phenomenon is proposed for double hit deformation.
\end{abstract}


Keywords: Dynamic Transformation; Thermomechanical Processing; Double-hit hot compression; Thermodynamics

\section{Introduction}

Components made of high strength steels used for critical applications such as turbine shafts and gears are manufactured by forging. The manufacturing process starts with an as-cast ingot, which is heated in the temperature range well above the $\mathrm{Ac}_{3}$ of the steel. The cast ingot, characterized by microstructural and chemical inhomogeneities, is then open die forged through multiple passes to give the as-cast ingot a final shape. The ultimate property of the forged ingot is reliant on the chronicle of the deformation parameters such as temperature, strain rate, interpass time, stress etc. Understanding the evolution of the phases during the high-temperature deformation process is essential. During this deformation process, various dynamic and static softening processes occur, such as dynamic transformation (DT), dynamic recrystallization (DRX) and static recrystallization (during interpass time) [1]. The occurrence of DT was first studied by Yada et al.[2, 3] in the 1980s. They explored the progress of DT under both laboratory testing conditions and pilot rolling mill trials. Later, they were able to follow the phenomenon in real-time when they deformed steel samples via torsion testing in an X-ray diffraction apparatus. Since then, several researches have been made on the transformation of DT, both using in-situ and ex-situ techniques [4-8].

The peak in the flow curve is usually a good indication that a softening process occurred. However, it does not provide any evidence about the exact initiations of DT or DRX. The initiation of DT and DRX usually occur at specific stress known as the critical stress $\left(\sigma_{c}\right)$, and their related strains are known as critical strain $\left(\varepsilon_{c}\right)$ [9]. To calculate the critical stress and critical strains, the double differentiation method [1] could be applied on the stress-strain curve obtained after deformation. This method has been proven to provide data about the initiation of various dynamic metallurgical softening phenomena such as twinning, recrystallization, and recovery [10]. Lately, this method has been used to identify the onset of dynamic transformation (DT) of austenite to ferrite during hot compression and rolling [7, 11-16]. Several researchers have shown that austenite can transform into ferrite by deformation at high temperature $[1,15,16]$. In the procedure of double differentiation, the stress-strain curve is primarily fitted with a polynomial function, then the strain hardening rate $(\theta)$ is determined using the relation: 


$$
\theta=\left(\frac{\delta \sigma}{\delta \varepsilon}\right)_{\dot{\varepsilon}}
$$

where, the stress $(\sigma)$ and strain $(\varepsilon)$ are obtained at a fixed strain rate $(\varepsilon$.$) .$

The minima were then calculated by taking the derivative of $\theta,[9,17]$ :

$$
\left(\frac{\delta}{\delta \sigma}\right)\left(\frac{\delta \theta}{\delta \sigma}\right)=0
$$

The minima of the $-\delta \theta / \delta \sigma$ versus the applied stress correspond to the onset of the softening mechanisms. In an earlier work [11], two softening mechanisms have been recognized during deformation of medium carbon low alloy steels at temperatures above the $\mathrm{Ae}_{3}$ (the equilibrium transformation temperature between the two-phase austenite and ferrite, and the single-phase austenite), which were associated with the occurrence of both dynamic transformation and dynamic recrystallization (DRX). It has also been reported that kinetics of DT is much faster than DRX through microstructural analysis [16].

Most of the previous works have been focused on extensive analysis of critical strains and stresses during single hit hot deformation [15, 16, 18-21]. Similar studies on double hit deformation, which closely resembles an actual manufacturing setting, are scarce. During double hit hot deformation, the first hit induces a pre-strain on the specimen [22]. The pre-strain causes formation of DT ferrite together with other metallurgical phenomena such as dynamic recovery and dynamic recrystallization. During the interval between passes, the DT ferrite may or may not re-transform to austenite due to the possibility of static softening processes. The static softening processes may lead to different microstructure as compared to the initial ones. The final microstructure after the second hit depends on factors such as deformation, strain rate, pre-strain, and interpass time. Thus, it is envisaged that double hit deformation would significantly influence the critical stresses for the onset of DT during the second hit and thus would directly impact the final microstructure as well. The present study focuses on the detailed explanation of the mechanisms occurring during interpass time and its impact on the final microstructure. In addition to that, calculation of the Gibbs energy change required for DT during the second hit deformation is complemented with microstructural analysis. 


\section{Materials and Methods}

The experiments involve as-cast medium carbon low alloy steel provided by Finkl Steel-Sorel, Quebec, Canada. The composition of the alloy steel is shown in Table 1, along with its equilibrium $\mathrm{Ae}_{3}$ temperature. This temperature was calculated using the JMatPro thermodynamic software employing General Steel module [23]. The central region of the as-cast ingot with dendritic microstructure was selected for the present study, and from there, the cylindrical specimens were machined with diameters and heights of $10 \mathrm{~mm}$ and $15 \mathrm{~mm}$, respectively. Double hit hot compression tests were performed using a Gleeble $3800^{\circledR}$ thermomechanical simulator following the procedures described in ASTM E209. The schematic diagram for double-hit compression tests is shown in Fig. 1. Two temperatures $\left(1200^{\circ} \mathrm{C}, 1150{ }^{\circ} \mathrm{C}\right)$, two strain rates $\left(0.25 \mathrm{~s}^{-1}\right.$ and $\left.0.5 \mathrm{~s}^{-1}\right)$, and three interpass times $(5,15 \& 25 \mathrm{~s})$ were employed in the experiments.

Table 1: Composition of as-cast medium-carbon low-alloy steel (wt. \%)

\begin{tabular}{cccccccc}
\hline C & Mn & Si & Mo & Cr & Other & $\begin{array}{c}\mathrm{Ae}_{3} \\
\text { Orthoequilibrium } \\
\text { temperature }\end{array}$ & $\begin{array}{c}\mathrm{Ae}_{3} \\
\text { Paraequilibrium } \\
\text { temperature }\end{array}$ \\
\hline 0.35 & 0.84 & 0.41 & 0.44 & 1.90 & Microalloying & $769.65^{\circ} \mathrm{C}$ & $748^{\circ} \mathrm{C}$ \\
\hline
\end{tabular}

The thermomechanical procedure consisted of heating the sample to $1260{ }^{\circ} \mathrm{C}$ at a heating rate of $2{ }^{\circ} \mathrm{C} / \mathrm{s}$ and soaking for 5 minutes $(300 \mathrm{~s})$ to homogenize the temperature and the microstructure. The samples were then cooled to the deformation temperature at a rate of $1{ }^{\circ} \mathrm{C} / \mathrm{s}$ before being compressed to a total true strain of 0.8 . The first deformation was applied at a true strain of 0.5 followed by 5,15 , and $25 \mathrm{~s}$ interpass time. The second pass was then applied at a true strain of 0.3 followed by water quenching. The samples were mechanically polished using conventional metallographic preparation techniques and final polished using a Vibromet巴 polisher. The EBSD analysis was performed using a Hitachi SU-70 field emission gun scanning electron microscope equipped with a Schottky emitter. Post-processing was done using the HKL Channel $5^{\mathrm{TM}}$ software and TSL OIM ${ }^{\mathrm{TM}}$. 


\section{Results and Discussions}

\subsection{Analysis of stress-strain curves}

Figs. 2a and $2 \mathbf{b}$ show the flow curves obtained from the double-hit deformation at temperatures of $1200{ }^{\circ} \mathrm{C}$ and $1150{ }^{\circ} \mathrm{C}$, strain rates of $0.25 \mathrm{~s}^{-1}$ and $0.5 \mathrm{~s}^{-1}$ and interpass times of 5,15 and $25 \mathrm{~s}$. The deformation temperatures are $358-408{ }^{\circ} \mathrm{C}$ above the equilibrium $\mathrm{Ae}_{3}$ temperature of the present alloy. As expected, the results show that the stress levels increase with an increase in strain rate; however, these stresses decrease with increasing deformation temperature. After the first deformation, both flow curves show a steady increase in stress and then gradually decrease after a peak stress of: i) $57.4 \mathrm{MPa}\left(0.25 \mathrm{~s}^{-1}, 1200^{\circ} \mathrm{C}\right)$, ii) $62.5 \mathrm{MPa}\left(0.5 \mathrm{~s}^{-1}, 1200^{\circ} \mathrm{C}\right)$, iii) $73.6 \mathrm{MPa}(0.25$ $\left.\mathrm{s}^{-1}, 1150{ }^{\circ} \mathrm{C}\right)$, and iv) $81.6 \mathrm{MPa}\left(0.5 \mathrm{~s}^{-1}, 1150{ }^{\circ} \mathrm{C}\right)$.

During the second deformation, a peak stress drop of approximately 15\% (compared to the first deformation) can be observed for both deformation conditions. Peak stresses of $53.2 \mathrm{MPa}$ and 57.4 MPa were detected for strain rates of $0.25 \mathrm{~s}^{-1}$ and $0.5 \mathrm{~s}^{-1}$, respectively, at $1200{ }^{\circ} \mathrm{C}$. On the other hand, for tests at $1150{ }^{\circ} \mathrm{C}$, peak stresses of $68.8 \mathrm{MPa}$ and $74.5 \mathrm{MPa}$ were measured for strain rates of $0.25 \mathrm{~s}^{-1}$ and $0.5 \mathrm{~s}^{-1}$, respectively.

It can be observed that the yield stress of the second deformation generally decreases with increasing interpass time under a similar deformation temperature and strain rate. During the interpass time, various dynamic and static metallurgical phenomena may occur and lead to an increase in work hardening in the second deformation [10]. In the present material, dynamic phase transformation and recrystallization may occur during strain hardening [24]. Since DRX leads to finer grains, the grain boundary area per unit volume increases and accelerates the nucleation rate for dynamic softening. Thus, this leads to a reduction in peak stress and strain during the second deformation.

A dedicated MATLAB ${ }^{\circledR}$ script was utilized to assess the occurrence of DRX and DT for the studied alloy at all deformation conditions. As mentioned above, this technique has been used by many researchers for the analysis of single hit deformation $[7,9,17,25,26]$, but not for double hit conditions.

Figs. 3a and $\mathbf{3 b}$ show the double differentiation curves for the first hit of the deformation schedule for two strain rates, i.e., $0.25 \mathrm{~s}^{-1}$ (Fig 3a) and $0.5 \mathrm{~s}^{-1}$ (Fig 3b). The curves display first and second minima, which represent the critical stresses at which DT $\left(1^{\text {st }}\right.$ minimum $)$ and DRX ( $2^{\text {nd }}$ minimum $)$ 
were initiated during deformation, respectively [1,9]. It can be observed from the double differential curves of the first hit deformation that critical stresses required for initiation of DT at $1200{ }^{\circ} \mathrm{C}$ are lower than that of the critical stresses at $1150{ }^{\circ} \mathrm{C}$ for both strain rates. These results are in accordance to previous research by the present authors that with the increase in the temperature, the diffusivity increases, which causes the carbon atoms to go out of austenite much faster and in turn transform to ferrite [18]. Moreover, the free energy difference between austenite and ferrite increases above the $\mathrm{Ae}_{3}$; however, around midway between the $\mathrm{Ae}_{3}$ and the delta ferrite formation temperature, this energy difference gradually decreases [15].

Since the focus of the present research is to investigate the occurrence of DT during the second hit, the DT critical stresses associated with the second hit deformation were calculated. Figs. 4a and $\mathbf{4 b}$ show the double differentiation curves for deformation temperatures of $1200{ }^{\circ} \mathrm{C}$ and 1150 ${ }^{\circ} \mathrm{C}$, and interpass times of $5 \mathrm{~s}, 15 \mathrm{~s}$, and $25 \mathrm{~s}$. Fig. $4 \mathbf{a}$ is associated with strain rate of $0.25 \mathrm{~s}^{-1}$ while Fig. $4 \mathrm{~b}$ is related to strain rate of $0.5 \mathrm{~s}^{-1}$. It can be observed that as the interpass time increases, the critical stresses for the initiation of DT decreases for all temperatures and strain rates. The probable reasons for the decrease in the critical stresses, as well as the peak stresses, would be discussed in detail in section 3.2 .

The critical stresses during double hit deformation are summarized in Fig. 5. Generally, the critical stresses in the second hit are lower than those of the first hit, which are shown in Figs. 5a-d. The difference can be associated with the presence of retained stress after the first hit, which provides part of the driving force needed to re-initiate DT. Interestingly, the lowest interpass time generates the lowest DT critical stress for all the deformation conditions. It can also be observed that for the same strain rate (i.e., Fig. 5a and 5c), the critical stresses are lower at a lower temperature. Moreover, for the same temperature (i.e., Fig. 5a and 5b), the highest strain rate requires a higher amount of stress for DT. Since double differentiation technique involves purely mathematical findings, a microstructural analysis was performed to validate the presence of dynamically transformed ferrite, as presented below.

\subsection{Microstructural features}

\subsubsection{Grain Boundary Maps}

Fig. 6 shows the grain boundary distribution map of the specimen after double hit deformation at $1200{ }^{\circ} \mathrm{C}$ and $1150{ }^{\circ} \mathrm{C}$ with strain rates of $0.25 \mathrm{~s}^{-1}$ (Fig. 6 (a) \& (c)) and $0.5 \mathrm{~s}^{-1}$ (Fig. 6 (b) \& (d)), 
respectively for $5 \mathrm{~s}$ interpass time and Fig. 7 (a-d) for $25 \mathrm{~s}$ interpass time for both deformation temperatures and strain rates. The employed interpass time is specified in the image. A close observation of the microstructures reveals a morphology composed of laths/plates (WF, shown with yellow arrows) and few quasi-polygonal grains (QPG, shown with black arrows) in all the microstructures.

The plates observed in the microstructure appear to have Widmanstätten type morphology in the plane containing the compression direction, which originates from the interior of the grains. This observation is consistent with the results of numerous researchers who have reported the presence of Widmanstätten type plates in the microstructure [1, 20,27]. Based on these studies, they attributed the phase transformation to the applied stress, which induces the displacive transformation of austenite to Widmanstätten ferrite. More specifically, Ghosh et al. [28] performed an atom probe tomography study to confirm such morphology. This morphology might be different from the plane normal to the compression direction, which is probably due to variant selection in the texture, as a consequence of the applied stress.

However, the presence of these plates and QPG vary with applied deformation conditions. During the deformation at $1200{ }^{\circ} \mathrm{C}$ and interpass time of 5 s (Figs. 6 (a) \& (b)), the appearance of these Widmanstätten-type plates is different for the two strain rates. At a strain rate of $0.25 \mathrm{~s}^{-1}$ (Fig. 6 a), it can be seen that the Widmanstätten-type plates nucleate from prior austenite grain boundaries and are 45 degrees with reference to the compression direction, whereas, for strain rate of $0.5 \mathrm{~s}^{-1}$ (Fig. 6 b), the ferrite plates seem to be disintegrated with smaller sizes. This structure may occur due to the increase in strain rate, which may lead to the disintegration of plates into grains, as reported in the literature [15].

At a lower temperature, i.e. $1150^{\circ} \mathrm{C}($ Figs. 6 (c) \& (d)), the presence of both plates and QPG can be seen in the microstructure. Surprisingly, at a strain rate of $0.5 \mathrm{~s}^{-1}$ (Fig. 6 d), the plates are observed clearly and not disintegrated, whereas at $0.25 \mathrm{~s}^{-1}$ (Fig. $6 \mathrm{c}$ ), there is a dominance of QPG with the presence of disintegrated plates.

With the increase in the interpass time i.e., $25 \mathrm{~s}$ (Fig. 7 (a-d)), the microstructure is different from the ones with the $5 \mathrm{~s}$ interpass time at respective deformation temperatures (Figs. 6 (a-d)). At deformation temperature of $1200{ }^{\circ} \mathrm{C}$ (Fig. 7 (a) \& (b)), the microstructure composes of mostly QPG with the presence of disintegrated plates while at deformation temperature of $1150{ }^{\circ} \mathrm{C}$ (Figs. 7 (c) \& (d)), it is composed of a mixture of disintegrated QPG as well as plates. Increasing the 
interpass time has a significant effect on the microstructure and will be discussed in detail in later sections. EBSD grain boundary distribution maps, reported in Fig. 6 \& Fig. 7 show that for all deformation conditions, significant low-angle grain boundaries (34.5 to 55.8\%) were present in the microstructure. This means that the region with LAGBs appears to be not fully recovered after the second hit or dislocations were generated during quenching. However, a significant number of ferrite grains with no presence of low angle grain boundaries (LAGBs) were observed in the laths and plates. This may be due to the fact that these grains were formed from austenite after DT initiation.

\subsubsection{Kernal Average Misorientation Method}

Grain boundary maps cannot confirm the presence of ferrite only by observation. Other techniques like XRD, optical microscopy, or secondary electron imaging are also inefficient to differentiate martensite (formed during water quenching) and DT ferrite as they have very little difference in the crystal structure (body-centered tetragonal, BCT for martensite) from the ferrite (bodycentered cubic, BCC. In order to overcome this shortcoming, the present study employed the Kernel Average Misorientation (KAM) method. In this approach, internal misorientation between grains is used to distinguish the BCT martensite from the BCC by means of EBSD images. Up to the third nearest neighbor was considered for calculating KAM values, and a threshold angle of $5^{\circ}$ was employed. Using the above criteria, the dynamic recovery process of the two phases was studied, and differentiation was successfully made between ferrite and austenite. Since ferrite has a higher stacking fault energy (SFE) than austenite, which would make dynamic recovery easier when it is further deformed to the final strain level $(\varepsilon=0.8)$. On the other hand, martensite laths (from prior austenite), which are formed due to shape deformation (displacive transformation), generate a higher amount of LAGBs, resulting in higher misorientations within the laths [27]. Thus, the area fractions with less than $2^{\circ}$ misorientation (i.e., $\mathrm{KAM} \leq 2^{\circ}$; green and blue regions) were considered as ferrite grains with minimal misorientations in the grains, and more than $2^{\circ}$ misorientation (i.e., $\mathrm{KAM} \geq 2^{\circ}$; yellow and red regions) were considered as martensite laths with high misorientations.

Figs. 8 (a-d) and Fig. 9 (a-d) show the KAM map for the specimen deformed at $5 \mathrm{~s}$ and $25 \mathrm{~s}$ interpass times, respectively. The blue and green regions represent grains with lower misorientation $\left(<2^{\circ}\right)$ and hence are ferrite grains, whereas, yellow and red regions have higher 
misorientations $\left(3^{\circ}-5^{\circ}\right)$ and are martensite grains. Upon observation and comparing with the grain boundary maps, the Widmanstätten type plates, and QPG are all blue or green colored, which confirms that these are dynamically transformed ferrite. Using the KAM method, the fraction of ferrite i.e., blue and green areas, was determined for all parameters.

The detailed fraction of ferrite grains can be found in Fig 10. It can be observed that as the strain rate is increased from 0.25 to $0.5 \mathrm{~s}^{-1}$, the fraction of ferrite grains decreases at all deformation temperature and interpass time. With higher interpass time, the fraction of ferrite grains reduces significantly. As expected, the amount of ferrite increases as the strain rate decreases due to larger diffusion distances of the alloying elements [12].

\subsubsection{Microstructure-Process interactions}

The microstructure analysis presented in section 3.2.1 and 3.2.2 has proved the presence of dynamically transformed ferrite formation from austenite during the double hit hot compression testing. However, it was found that the structure of DT ferrite was different for different testing parameters. In some cases, the Widmanstatten ferrite plates were seen, and in others, QPG was dominant as also reported by the authors in a previous study after single hit compression [12]. However, critical stress for initiation of DT, the ferrite fraction, and disintegration of plates, as well as QPG, are differentiators between the two deformation modes, or in other words, it appears that the interpass time between the two hits plays an important role in the operating mechanisms.

\section{a. Role of interpass times}

The interpass time plays a critical role in microstructure evolution. During the interpass time, various softening mechanisms activate, such as static recrystallization (SRX) [29, 30], metadynamic recrystallization (MDRX) [31] and retransformation of DT ferrite to austenite (RT). Retransformation back to austenite from DT ferrite has been reported by few researchers $[1,26$, $28,32]$. They have reported that as the interpass time increases, the retransformation increases; however, the kinetics of retransformation is slower than forward transformation. For example, in one of the researches in X70 steel [33], it was found that after 5s of interpass time, the amount of ferrite was reduced by $34.6 \%$ to $28 \%$, and after 40 s it further reduced to $6.5 \%$. In the present case, 
the maximum interpass time is $25 \mathrm{~s}$ and it is envisaged that this would initiate the reverse transformation from ferrite formed during the first deformation to austenite.

The effect of carbon diffusion on the reverse transformation must therefore be analyzed. Since there is no stress applied during the interpass times, the dominant diffusion mechanism would be lattice diffusion. Lattice diffusion coefficient $\left(D_{L}\right)$ and diffusion distance $(x \mu m)$ is calculated using the following equation

$$
\begin{gathered}
D_{L}=D_{0 L} \exp \left(-\frac{Q_{L}}{R T}\right) \\
x=\sqrt{D_{L} \times t}
\end{gathered}
$$

Where, $\mathrm{t}$ is time in seconds

Table 2: Material data for carbon in medium carbon low alloy steel.

Pre-exponential of lattice diffusion for Carbon $D_{0 L}\left(\frac{m^{2}}{s}\right)[34]$

$7.9 \times 10^{-7}$

Activation energy of lattice diffusion for Carbon, $Q_{L}\left(\frac{K J}{m o l e}\right)[34]$

Upon calculating, it was found that the diffusion distance increased with increasing the interpass time. It must be noted that, the diffusivity of the carbon atoms remains the same for respective deformation temperatures and only diffusion distance changes. The carbon atom diffuses into the ferrite grains to form austenite, which hold a higher fraction of carbon due to its crystal structure [35]. As the diffusion distance increases with the interpass times, more and more carbon atoms diffuse, which results to retransformation of DT ferrite to austenite. In order to validate this lattice diffusion analysis, ferrite fraction after the interpass time were calculated and the results are presented in Fig. 11.

EBSD KAM maps of the samples were examined for different interpass times and are named as break interpass tests. Fig. 12 shows the KAM map of samples deformed at a temperature of 1200 ${ }^{\circ} \mathrm{C}$ and $1150{ }^{\circ} \mathrm{C}$, strain rate of $0.25 \mathrm{~s}^{-1}$ and $0.5 \mathrm{~s}^{-1}$ till strain of 0.5 and then held at similar temperature for $5 \mathrm{~s}, 15 \mathrm{~s}$ and $25 \mathrm{~s}$. The samples were water quenched immediately after the respective holding times to preserve the final microstructure and the ferrite fractions were calculated for each testing condition. The results reported in Fig. 13 shows that as the interpass time increases, the ferrite fraction reduces significantly. The DT ferrite during interpass times must 
have transformed back to austenite, and upon quenching, the austenite transforms to martensite. The interpass time also leads to a finer microstructure as observed at $25 \mathrm{~s}$. This may be due to static or metadynamic recrystallization, where the grains recover and start to grow.

\section{b. Role of second deformation}

In addition to the interpass time which plays a significant role in the microstructure and ferrite fraction at the final stage, other factors, such as critical stress and strains, also play a significant role in the microstructure evolution, as discussed below,

It was found in the above sections that for all deformation conditions, the critical stresses for initiation of DT as well as the peak stresses decreased with increasing interpass times. Furthermore, it was found that the ferrite fraction was decreasing with the increase in the interpass times. In order to identify the possible operating mechanism, the critical strains corresponding to the critical stresses were calculated and the results are shown in Fig. 14.

The obtained results show clearly that as the interpass time increases, the critical strains for the initiation of DT increases significantly as well. For example, in the case of the test at $1200^{\circ} \mathrm{C}$ and $0.25 \mathrm{~s}^{-1}$, the critical strains shows an increase from around $400 \%$ when the interpass time increases from $5 \mathrm{~s}$ to $25 \mathrm{~s}$.

In the case of the lowest interpass time, i.e., $5 \mathrm{~s}$, the critical strain is just 0.016 (or total strain of 0.5016 after the second hit), which gives enough strain energy for the transformation of ferrite from austenite. Whereas, in the case of $25 \mathrm{~s}$, since the critical strain is 0.109 (or total strain of 0.609 after the second hit), the transformation to ferrite would occur for the rest of the strain (dynamically), which allows less time for transformation as compared to $5 \mathrm{~s}$. Moreover, the critical strains for DRX is higher in case of $25 \mathrm{~s}(0.23)$, which causes the delay in the formation of new

ferrite grains due to nucleation. It is evident from the microstructures of $25 \mathrm{~s}$ interpass times that the new grain nucleation have been observed through a grain boundary bulging mechanism (red arrows).

This adds to the interpass effect where, as the time increases, the retransformation to austenite increases. Since the austenite fraction is higher and the critical strain is higher as well, the forward transformation would be less since there will not be enough strain energy. 


\subsection{Thermodynamic analysis}

The deformation is known to provide an additional driving force to transform austenite into ferrite above the $\mathrm{Ae}_{3}$ temperature [32]. This added energy increases the austenite free energy, which leads to less stable austenite. Thus, it is essential to understand the equilibrium behavior of the material. The dependence of equilibrium phase fractions on temperature is displayed in Fig. 15a. The presence of each phases in the equilibrium condition is highly dependent on temperature. In the present study, the main region of interest is between $700{ }^{\circ} \mathrm{C}$ to $800{ }^{\circ} \mathrm{C}$, as shown in Fig. $\mathbf{1 5 b}$. Above $792{ }^{\circ} \mathrm{C}$, the phase is completely austenite. On the other hand, below $792{ }^{\circ} \mathrm{C}$, ferrite starts to form. It is widely known that the driving force to transform an austenite phase into ferrite under static conditions is the Gibbs energy difference $\left(\Delta \mathrm{G}_{\alpha-\gamma}\right)$ between the phases. This approach will also give an idea regarding the phase fraction at a specific temperature, which is employed to develop equilibrium phase diagrams.

The phase fraction of DT ferrite after double-hit tests, shown in Fig. 10, was employed to determine the free energy difference between ferrite and austenite $\left(\Delta \mathrm{G}_{\alpha-\gamma}\right)$. For example, the presence of $70 \%$ DT ferrite $\left(1200{ }^{\circ} \mathrm{C}\right.$, strain rate of $0.25 \mathrm{~s}^{-1}$ and interpass time of $\left.5 \mathrm{~s}\right)$, assuming that this fraction was entirely formed at deformation temperature, means that the free energy state is equivalent to that of the equilibrium state at $750{ }^{\circ} \mathrm{C}$ (see Fig. 15b). Thus, in this example, the difference between the free energy of austenite at deformation temperature and at $750{ }^{\circ} \mathrm{C}$ is the driving force applied to austenite to initiate the phase transformation. The illustration of this approach is presented in Fig. 16. Here the values above the zero line mean that ferrite is not stable. The difference in $\Delta \mathrm{G}_{\alpha-\gamma}$ between the stable and unstable regions of ferrite can provide a quantitative amount of the energy supplied to transform a fraction of austenite into ferrite. Note that this method assumes a diffusional transformation mechanism. Assuming that the mechanism of DT is diffusional, Table 3 provides values of $\Delta \mathrm{G}$ added to the austenite during deformation, referred here as the driving force. In all the experiments, the driving force ranges from 260 to $300 \mathrm{~J} / \mathrm{mol}$. Higher strain rates provide a lower fraction of ferrite, which can be an indication that diffusion plays a role in DT. Note that higher strain rates offer less time to allow for phase transformation during deformation. The proposed method permits the estimation of the free energy of austenite by the end of thermomechanical processing. 
Table 3. Free energy added to the austenite phase based on the volume fraction of ferrite.

\begin{tabular}{|c|c|c|c|c|c|c|}
\hline $\begin{array}{c}\text { Deformation } \\
\text { Temperature }\end{array}$ & $\begin{array}{c}\text { Strain } \\
\text { Rate }\end{array}$ & $\begin{array}{c}\text { Interpass } \\
\text { Time }\end{array}$ & $\begin{array}{c}\Delta \mathbf{G \alpha} \boldsymbol{\gamma} \text { at } \\
\text { Def. } \\
\text { Temp }\end{array}$ & $\begin{array}{c}\text { Percentage of } \\
\text { DT ferrite }\end{array}$ & $\begin{array}{c}\Delta \mathbf{G a}-\boldsymbol{\gamma} \\
\text { based on } \\
\text { ferrite }\end{array}$ & $\begin{array}{c}\Delta \mathbf{G} \text { added } \\
\text { to } \\
\text { austenite }\end{array}$ \\
\hline $120{ }^{\circ} \mathrm{C}$ & $0.25 \mathrm{~s}^{-1}$ & $5 \mathrm{~s}$ & $225.5 \mathrm{~J} / \mathrm{mol}$ & $70 \%$ & $-77.2 \mathrm{~J} / \mathrm{mol}$ & $302.7 \mathrm{~J} / \mathrm{mol}$ \\
\hline $120{ }^{\circ} \mathrm{C}$ & $0.25 \mathrm{~s}^{-1}$ & $15 \mathrm{~s}$ & $225.5 \mathrm{~J} / \mathrm{mol}$ & $34 \%$ & $-28.7 \mathrm{~J} / \mathrm{mol}$ & $254.2 \mathrm{~J} / \mathrm{mol}$ \\
\hline $1200^{\circ} \mathrm{C}$ & $0.25 \mathrm{~s}^{-1}$ & $25 \mathrm{~s}$ & $225.5 \mathrm{~J} / \mathrm{mol}$ & $21 \%$ & $-24.2 \mathrm{~J} / \mathrm{mol}$ & $249.7 \mathrm{~J} / \mathrm{mol}$ \\
\hline $120{ }^{\circ} \mathrm{C}$ & $0.50 \mathrm{~s}^{-1}$ & $5 \mathrm{~s}$ & $225.5 \mathrm{~J} / \mathrm{mol}$ & $44 \%$ & $-40.1 \mathrm{~J} / \mathrm{mol}$ & $265.6 \mathrm{~J} / \mathrm{mol}$ \\
\hline $1200^{\circ} \mathrm{C}$ & $0.50 \mathrm{~s}^{-1}$ & $15 \mathrm{~s}$ & $225.5 \mathrm{~J} / \mathrm{mol}$ & $39 \%$ & $-33.9 \mathrm{~J} / \mathrm{mol}$ & $259.4 \mathrm{~J} / \mathrm{mol}$ \\
\hline $120{ }^{\circ} \mathrm{C}$ & $0.50 \mathrm{~s}^{-1}$ & $25 \mathrm{~s}$ & $225.5 \mathrm{~J} / \mathrm{mol}$ & $34 \%$ & $-28.7 \mathrm{~J} / \mathrm{mol}$ & $254.2 \mathrm{~J} / \mathrm{mol}$ \\
\hline $1150^{\circ} \mathrm{C}$ & $0.25 \mathrm{~s}^{-1}$ & $5 \mathrm{~s}$ & $235.4 \mathrm{~J} / \mathrm{mol}$ & $62 \%$ & $-64.3 \mathrm{~J} / \mathrm{mol}$ & $299.7 \mathrm{~J} / \mathrm{mol}$ \\
\hline $1150^{\circ} \mathrm{C}$ & $0.25 \mathrm{~s}^{-1}$ & $15 \mathrm{~s}$ & $235.4 \mathrm{~J} / \mathrm{mol}$ & $31 \%$ & $-26.4 \mathrm{~J} / \mathrm{mol}$ & $261.8 \mathrm{~J} / \mathrm{mol}$ \\
\hline $1150^{\circ} \mathrm{C}$ & $0.25 \mathrm{~s}^{-1}$ & $25 \mathrm{~s}$ & $235.4 \mathrm{~J} / \mathrm{mol}$ & $27 \%$ & $-22.01 \mathrm{~J} / \mathrm{mol}$ & $257.4 \mathrm{~J} / \mathrm{mol}$ \\
\hline $1150^{\circ} \mathrm{C}$ & $0.50 \mathrm{~s}^{-1}$ & $5 \mathrm{~s}$ & $235.4 \mathrm{~J} / \mathrm{mol}$ & $42 \%$ & $-37.8 \mathrm{~J} / \mathrm{mol}$ & $273.2 \mathrm{~J} / \mathrm{mol}$ \\
\hline $1150^{\circ} \mathrm{C}$ & $0.50 \mathrm{~s}^{-1}$ & $15 \mathrm{~s}$ & $235.4 \mathrm{~J} / \mathrm{mol}$ & $37 \%$ & $-30.9 \mathrm{~J} / \mathrm{mol}$ & $266.3 \mathrm{~J} / \mathrm{mol}$ \\
\hline $1150^{\circ} \mathrm{C}$ & $0.50 \mathrm{~s}^{-1}$ & $25 \mathrm{~s}$ & $235.4 \mathrm{~J} / \mathrm{mol}$ & $31 \%$ & $-26.4 \mathrm{~J} / \mathrm{mol}$ & $261.8 \mathrm{~J} / \mathrm{mol}$ \\
\hline
\end{tabular}

\section{Conclusions}

The occurrence of dynamic transformation of austenite to ferrite during double hit hot deformation tests in a medium-carbon low-alloy steel and the influence of interpass time on the occurrence of DT were investigated. Based on the analysis of the flow curves by means of double differentiation method and microstructural analysis using electron microscopy, it was proved that DT takes place after the $2^{\text {nd }}$ hit. Fraction of ferrite was higher at higher temperature, lower strain rate, and with least interpass time.

Using KAM technique, it was determined that with the increase in interpass time, the fraction of ferrite was significantly reduced. It was observed that low strain rates resulted in the dominance of DT ferrite with Widmanstätten morphology, while at a higher strain rate, quasi-polygonal morphology was found.

Analysis of carbon diffusion using lattice diffusion showed higher diffusion distances at higher interpass times. On this basis, correlations between the ferrite fraction, the diffusion distance of carbon atoms was established. With the increase in carbon diffusion, the ferrite retransformed back to austenite, which resulted in delayed initiation of DT during the second hit thus, resulting in lower ferrite fraction at the final stage. 
A better understanding of the thermodynamics of DT ferrite formation was done by using the measured volume fraction of DT ferrite formed to measure the change of free energy of austenite.

\section{Acknowledgments}

The authors are very grateful to Finkl Steel for providing the specimens for the present research. They would also like to thank the National Science Engineering Research Council (NSERC) Canada for their support in the framework of a Collaborative Research and Development project (CRD). The authors are grateful to NSERC Discovery, New Brunswick Innovation fund (NBIF) and Canada Foundation for Innovation (CFI).

\section{The authors have no conflict of interest.}

\section{References}

[1] C. Ghosh, C. Aranas Jr, J.J. Jonas, Dynamic transformation of deformed austenite at temperatures above the Ae3, Progress in Materials Science 82 (2016) 151-233.

[2] H. Yada, C.-M. Li, H. Yamagata, Dynamic \&gamma;\&rarr;\&alpha; Transformation during Hot Deformation in Iron\&ndash;Nickel\&ndash;Carbon Alloys, ISIJ International 40(2) (2000) 200-206. [3] H. Yada, Y. Matsumura, K. Nakajima, Ferritic steel having ultra-fine grains and a method for producing the same, Google Patents, 1984.

[4] V.V. Basabe, J.J. Jonas, C. Ghosh, Formation of Strain-induced Ferrite in Low Carbon Steels at Temperatures Above the Ae<sub>3</sub>, ISIJ International 53(12) (2013) 2233-2241.

[5] E. Essadiqi, J.J. Jonas, Effect of deformation on the austenite-to-ferrite transformation in a plain carbon and two microalloyed steels, Metallurgical Transactions A 19(3) (1988) 417-426.

[6] K. Chadha, D. Shahriari, C. Aranas, Jr., L.-P. Lapierre-Boire, M. Jahazi, On the Role of Chromium in Dynamic Transformation of Austenite, Metals and Materials International 25(3) (2019) 559-569.

[7] C. Aranas Jr, S. Rodrigues, F. Siciliano, J. Jonas, In-situ X-ray diffraction evidence of dynamic transformation of austenite to ferrite during hot compression test in the single austenite phase field, Scripta Materialia 177 (2020) 86-90.

[8] K. Chadha, Microstructure evolution of medium carbon low alloy steel during ingot breakdown process, École de technologie supérieure, 2018.

[9] J.J. Jonas, C. Ghosh, X. Quelennec, V.V. Basabe, The Critical Strain for Dynamic Transformation in Hot Deformed Austenite, ISIJ International 53(1) (2013) 145-151.

[10] S. Bao, G. Zhao, C. Yu, Q. Chang, C. Ye, X. Mao, Recrystallization behavior of a Nb-microalloyed steel during hot compression, Applied Mathematical Modelling 35(7) (2011) 3268-3275.

[11] K. Chadha, Z. Ahmed, C. Aranas Jr, D. Shahriari, M. Jahazi, Influence of strain rate on dynamic transformation of austenite in an as-cast medium-carbon low-alloy steel, Materialia 1 (2018) 155-167.

[12] K. Chadha, D. Shahriari, C.J. Aranas, L.-P. Lapierre-Boire, M. Jahazi, On the role of chromium in dynamic transformation of austenite, Metals and Materials International 25(3) (2019) 559-569. 
[13] C. Aranas Jr, T. Nguyen-Minh, R. Grewal, J.J. Jonas, Flow softening-based formation of Widmanstätten ferrite in a $0.06 \%$ C steel deformed above the Ae3, ISIJ International 55(1) (2015) 300307.

[14] C. Aranas Jr, S.F. Rodrigues, R. Grewal, J.J. Jonas, Ferrite formation above the Ae3 temperature during the torsion simulation of strip rolling, ISIJ International 55(11) (2015) 2426-2434.

[15] R. Grewal, C. Aranas Jr, K. Chadha, D. Shahriari, M. Jahazi, J.J. Jonas, Formation of Widmanstätten ferrite at very high temperatures in the austenite phase field, Acta Materialia 109 (2016) 23-31.

[16] C. Aranas, S. Rodrigues, A. Fall, M. Jahazi, J. Jonas, Determination of the critical stress associated with dynamic phase transformation in steels by means of free energy method, Metals 8(5) (2018) 360.

[17] C. Ghosh, V.V. Basabe, J.J. Jonas, Determination of the critical strains for the initiation of dynamic transformation and dynamic recrystallization in four steels of increasing carbon contents, steel research international 84(5) (2013) 490-494.

[18] K. Chadha, Z. Ahmed, C. Aranas, D. Shahriari, M. Jahazi, Influence of strain rate on dynamic transformation of austenite in an as-cast medium-carbon low-alloy steel, Materialia 1 (2018) 155-167.

[19] C. Aranas Jr, T. Nguyen-Minh, R. Grewal, J.J. Jonas, Flow Softening-based Formation of Widmanstätten Ferrite in a $0.06 \%$ C Steel Deformed Above the Ae<sub $>3</$ sub $>$, ISIJ International 55(1) (2015) 300-307.

[20] N. Park, S. Khamsuk, A. Shibata, N. Tsuji, Occurrence of dynamic ferrite transformation in lowcarbon steel above Ae3, Scripta Materialia 68(7) (2013) 538-541.

[21] H.-B. Li, M.-S. Chen, Y.-Q. Tian, L.-S. Chen, L.-Q. Chen, Ultra-fine-grained ferrite prepared from dynamic reversal austenite during warm deformation, Acta Metallurgica Sinica (English Letters) 33(2) (2020) 290-298.

[22] X. Wang, K. Chandrashekhara, M.F. Buchely, S. Lekakh, D.C. Van Aken, R.J. O'Malley, G.W. Ridenour, E. Scheid, Experiment and simulation of static softening behavior of alloyed steel during round bar hot rolling, Journal of Manufacturing Processes 52 (2020) 281-288.

[23] N. Saunders, U. Guo, X. Li, A. Miodownik, J.-P. Schillé, Using JMatPro to model materials properties and behavior, Jom 55(12) (2003) 60-65.

[24] Y.C. Lin, M.-S. Chen, J. Zhong, Study of metadynamic recrystallization behaviors in a low alloy steel, Journal of Materials Processing Technology 209(5) (2009) 2477-2482.

[25] E. Poliak, J. Jonas, A one-parameter approach to determining the critical conditions for the initiation of dynamic recrystallization, Acta Materialia 44(1) (1996) 127-136.

[26] C. Ghosh, V.V. Basabe, J.J. Jonas, Y.-M. Kim, I.-H. Jung, S. Yue, The dynamic transformation of deformed austenite at temperatures above the Ae3, Acta Materialia 61(7) (2013) 2348-2362.

[27] N. Park, A. Shibata, D. Terada, N. Tsuji, Flow stress analysis for determining the critical condition of dynamic ferrite transformation in 6Ni-0.1 C steel, Acta materialia 61(1) (2013) 163-173.

[28] C. Ghosh, V.V. Basabe, J.J. Jonas, S. Yue, X.Y. Xiong, Dynamic transformation behavior of a deformed high carbon steel at temperatures above the Ae3, ISIJ international 53(5) (2013) 900-908.

[29] S.-H. Cho, K.-B. Kang, J.J. Jonas, The dynamic, static and metadynamic recrystallization of a Nbmicroalloyed steel, ISIJ international 41(1) (2001) 63-69.

[30] K. Chadha, D. Shahriari, R. Tremblay, P.P. Bhattacharjee, M. Jahazi, Deformation and Recrystallization Behavior of the Cast Structure in Large Size, High Strength Steel Ingots:

Experimentation and Modeling, Metallurgical and Materials Transactions A 48(9) (2017) 4297-4313. [31] K. Chadha, D. Shahriari, M. Jahazi, Modeling metadynamic recrystallization of a die steel during ingot breakdown process, MATEC Web of Conferences, EDP Sciences, 2016, p. 06004.

[32] C. Ghosh, V.V. Basabe, J.J. Jonas, Thermodynamics of dynamic transformation of hot deformed austenite in four steels of increasing carbon contents, Materials Science and Engineering: A 591 (2014) 173-182. 
[33] S.F. Rodrigues, C. Aranas Jr, J.J. Jonas, Retransformation Behavior of Dynamically Transformed Ferrite during the Simulated Plate Rolling of a Low C and an X70 Nb Steel, ISIJ International advpub (2017).

[34] E. Brandes, G. Brook, P. Paufler, Smithells Metals Reference Book. Butterworth-Heinemann Ltd., Oxford, 1992. 1746 Seiten, Preis 150f, ISBN 0-7506-1020-4, Crystal Research and Technology 28(4) (1993) 530-530.

[35] J. Ågren, Computer simulations of the austenite/ferrite diffusional transformations in low alloyed steels, Acta Metallurgica 30(4) (1982) 841-851.

\section{List of Figures}

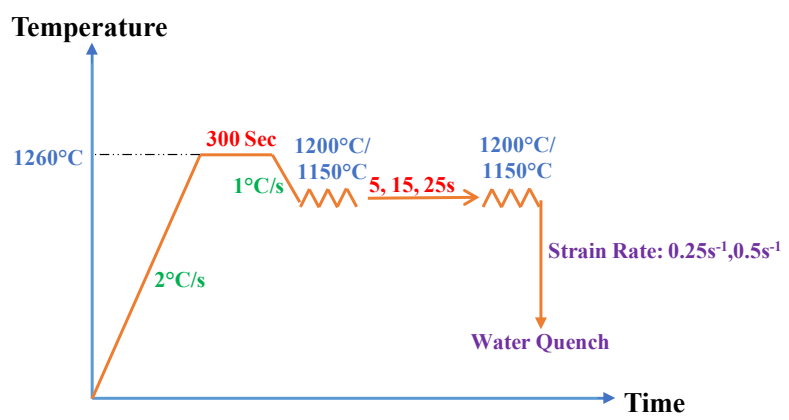

Figure 1. Schematic diagram of thermomechanical schedule for double hit hot compression tests of as-cast medium-carbon low-alloy steel.

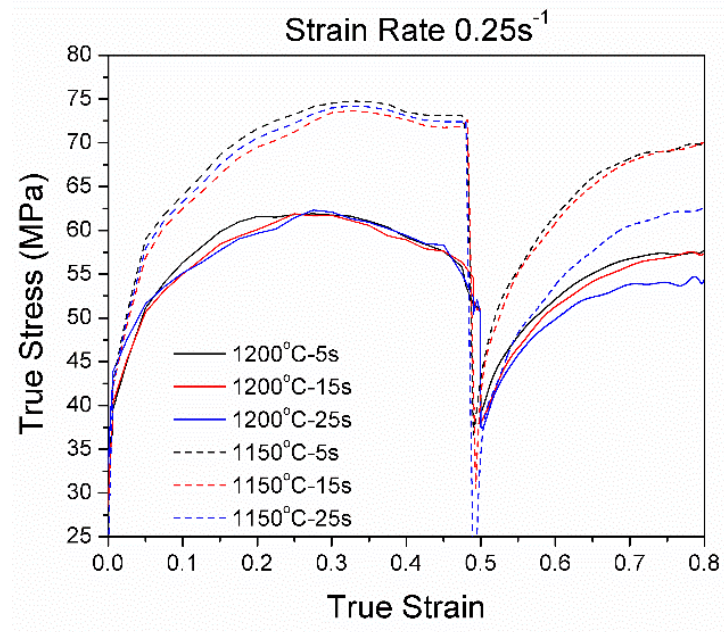

(a)

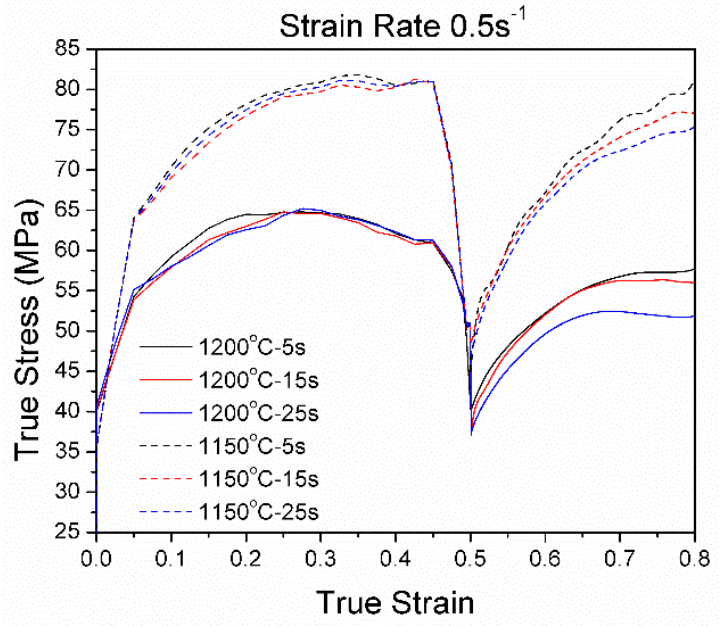

(b)

Figure 2. Stress-strain curves of as-cast medium-carbon low-alloy steel during double hit hot isothermal compression at strain rates of at deformation temperatures of $1200{ }^{\circ} \mathrm{C}$ and $1150{ }^{\circ} \mathrm{C}$ at strain rates of (a) $0.25 \mathrm{~s}^{-1}$ and (b) $0.5 \mathrm{~s}^{-1}$. 


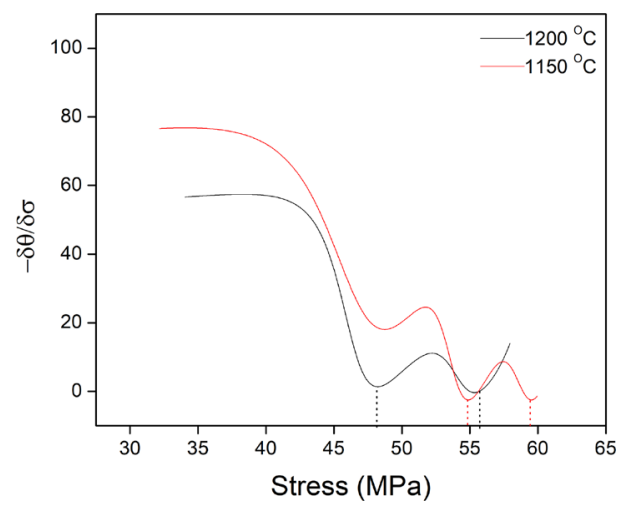

(a)

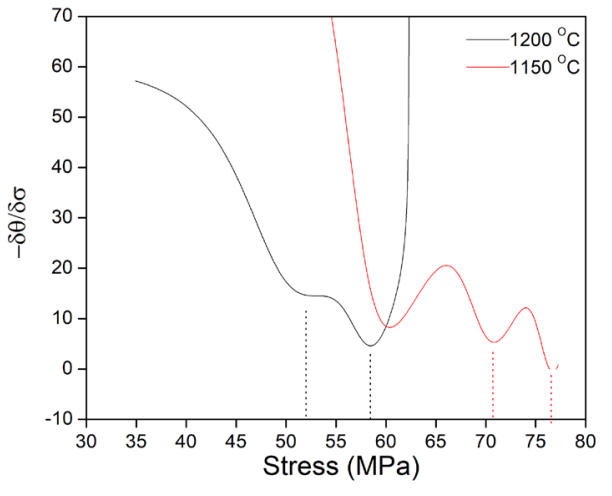

(b)

Figure 3. Critical stresses and strains for DT and DRX for the first hit. The experiment was carried out at $1200{ }^{\circ} \mathrm{C}$ and $1150{ }^{\circ} \mathrm{C}$ and strain rate of (a) $0.25 \mathrm{~s}^{-1}$ and (b) $0.5 \mathrm{~s}^{-1}$.

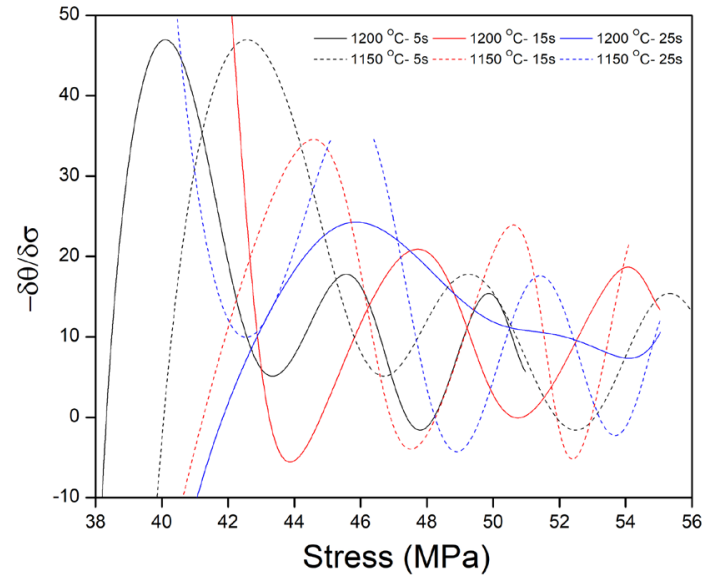

(a)

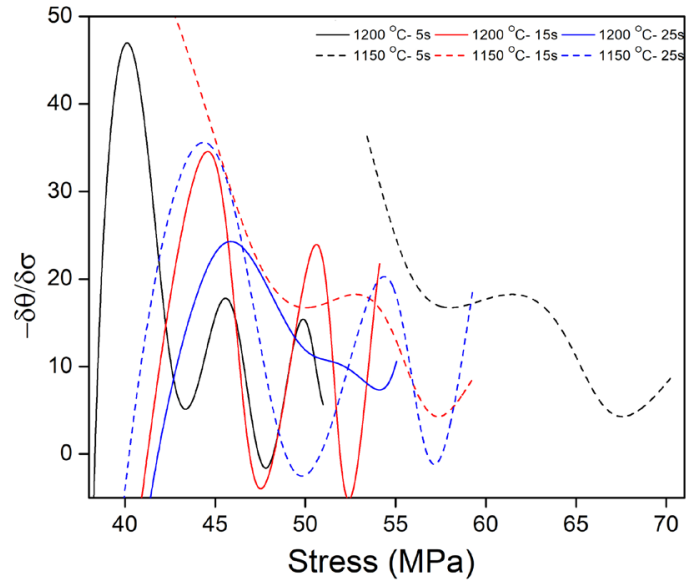

(b)

Figure 4. Critical stresses and strains for DT and DRX for the second hit with interpass times of 5,15 and $25 \mathrm{~s}$. The experiment was carried out at $1200^{\circ} \mathrm{C}$ and $1150{ }^{\circ} \mathrm{C}$ and strain rate of (a)

$$
0.25 \mathrm{~s}^{-1} \text { and (b) } 0.5 \mathrm{~s}^{-1} \text {. }
$$




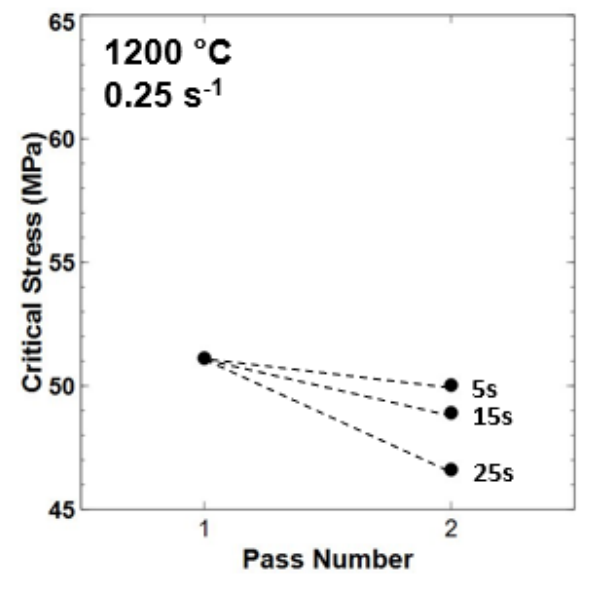

(a)

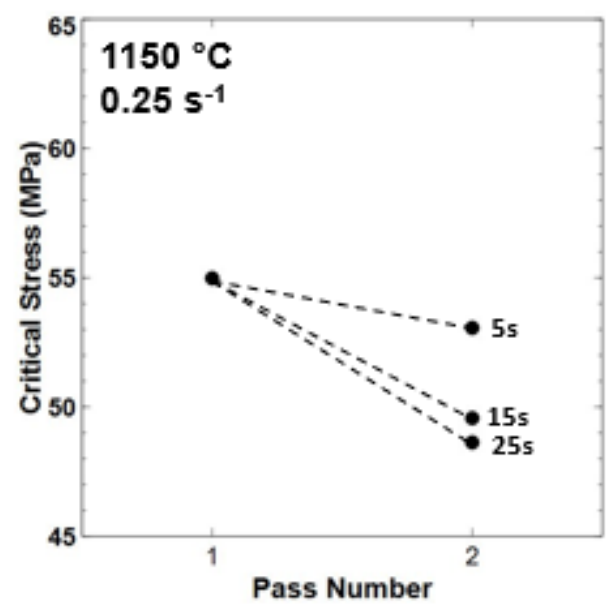

(c)

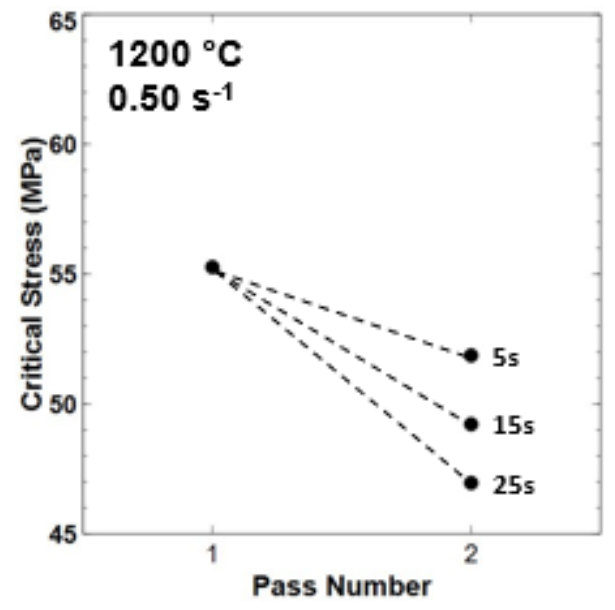

(b)

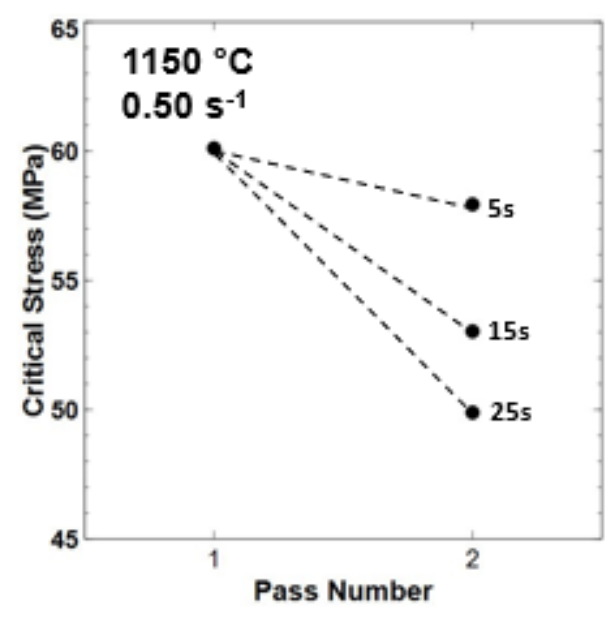

(d)

Figure 5. Critical stresses for initiation of dynamic transformation (DT) for first and second hit hot deformation tests determined over the temperature of $1150{ }^{\circ} \mathrm{C}$ to $1200{ }^{\circ} \mathrm{C}$ and strain rates of $0.25 \mathrm{~s}^{-1}$ and $0.5 \mathrm{~s}^{-1}$.
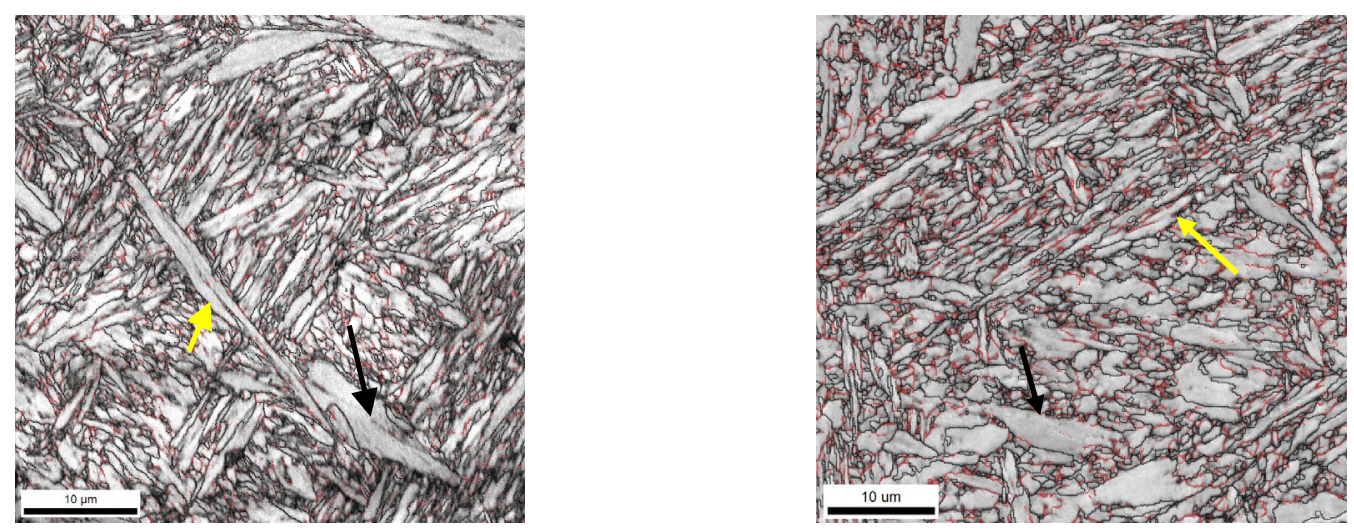
(a)

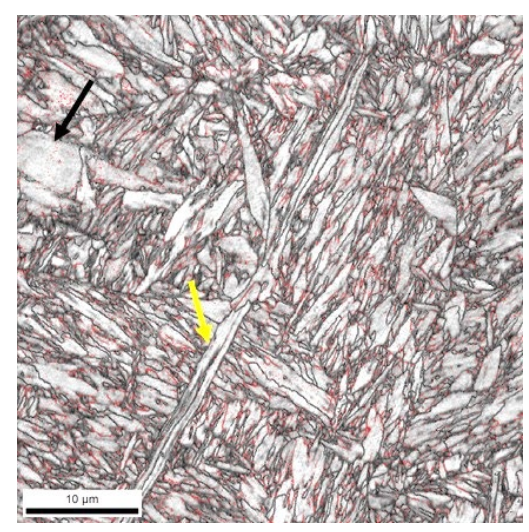

(c) (b)

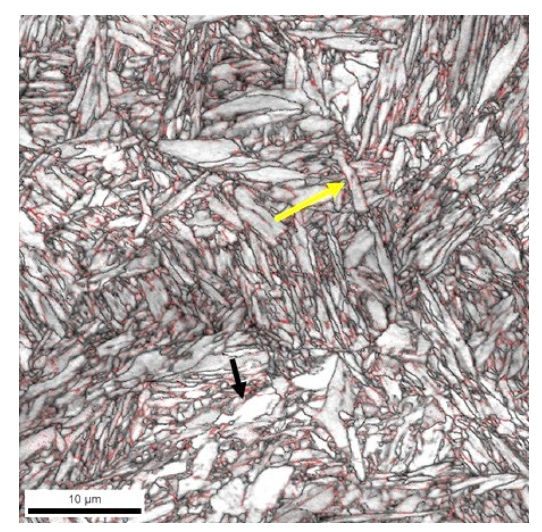

(d)

Figure 6. EBSD grain boundary map of medium-carbon low-alloy steel deformed by double hit deformation at (a) $1200^{\circ} \mathrm{C}-0.25 \mathrm{~s}^{-1}-5 \mathrm{~s}$, (b) $1200^{\circ} \mathrm{C}-0.5 \mathrm{~s}^{-1}-5 \mathrm{~s}$,

(c) $1150{ }^{\circ} \mathrm{C}-0.25 \mathrm{~s}^{-1}-5 \mathrm{~s}$ and (d) $1150{ }^{\circ} \mathrm{C}-0.5 \mathrm{~s}^{-1}-5 \mathrm{~s}$. Black lines denote HAGB and red lines denote LAGB.

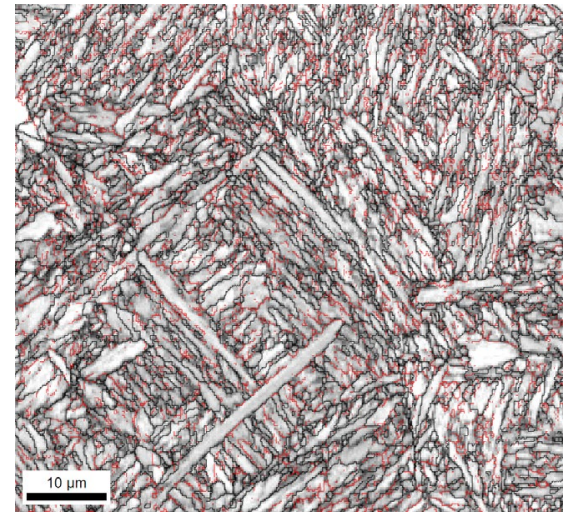

(a)

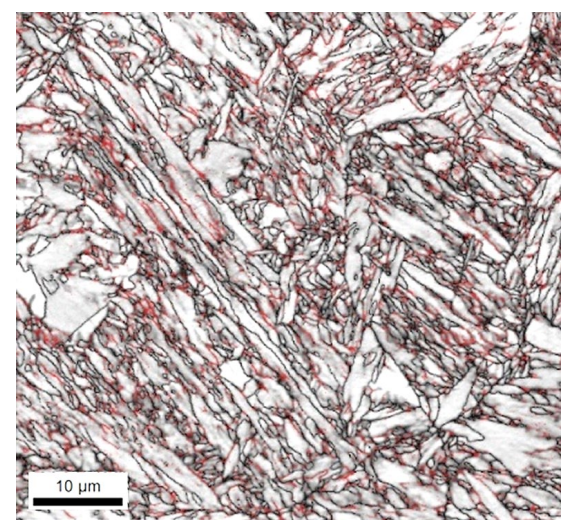

(c)

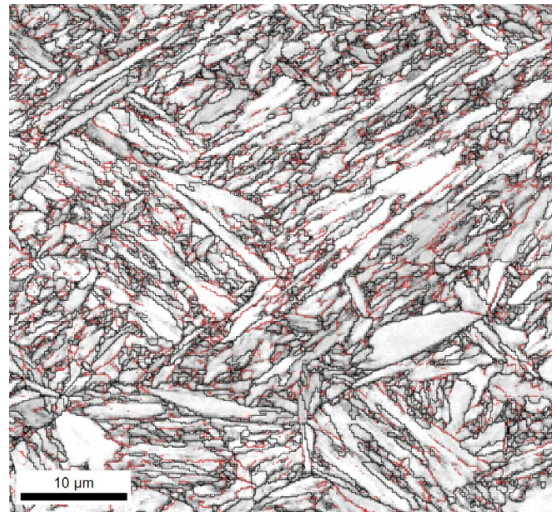

(b)

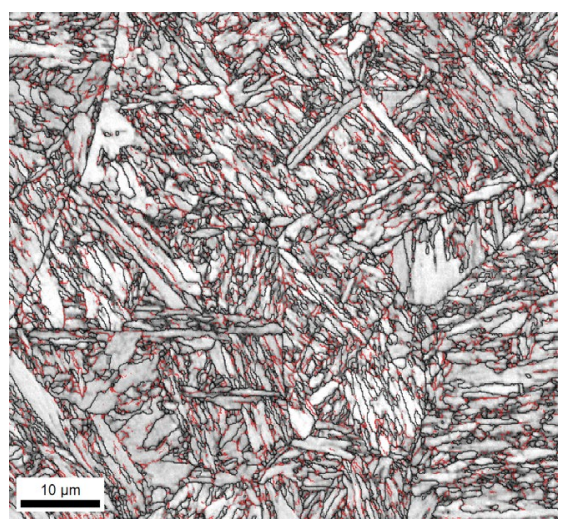

(d) 
Figure 7. EBSD grain boundary map of medium-carbon low-alloy steel deformed by double hit deformation at (a) $1200^{\circ} \mathrm{C}-0.25 \mathrm{~s}^{-1}-25 \mathrm{~s}$, (b) $1200^{\circ} \mathrm{C}-0.5 \mathrm{~s}^{-1}-25 \mathrm{~s}$,

(c) $1150{ }^{\circ} \mathrm{C}-0.25 \mathrm{~s}^{-1}-25 \mathrm{~s}$ and (d) $1150{ }^{\circ} \mathrm{C}-0.5 \mathrm{~s}^{-1}-25 \mathrm{~s}$. Black lines denote HAGB and red lines denote LAGB.

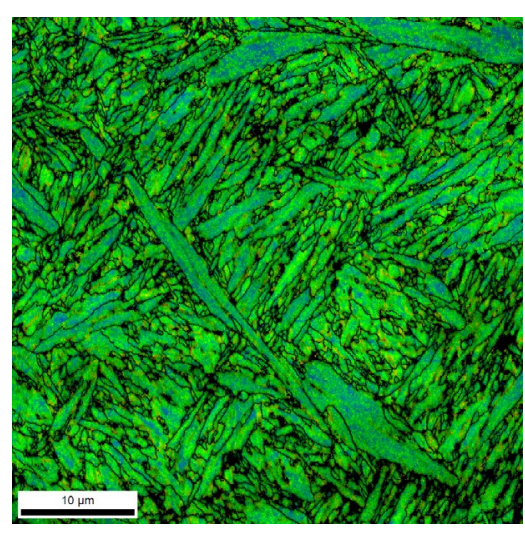

(a)

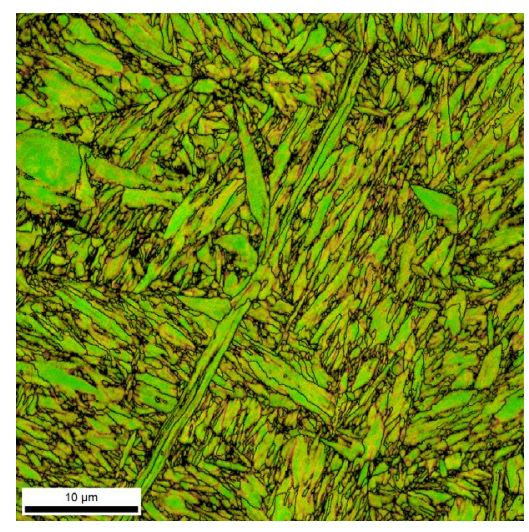

(c)

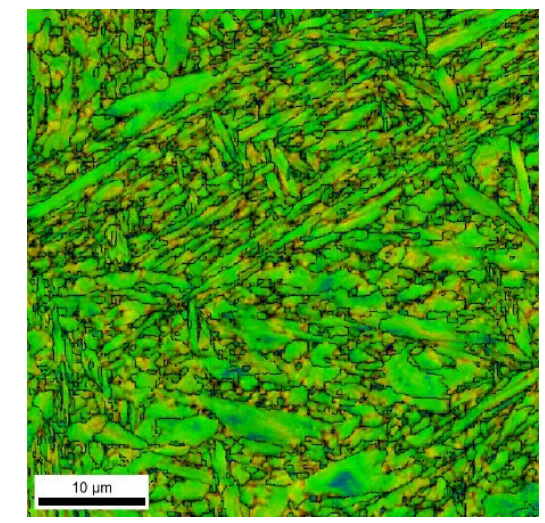

(b)
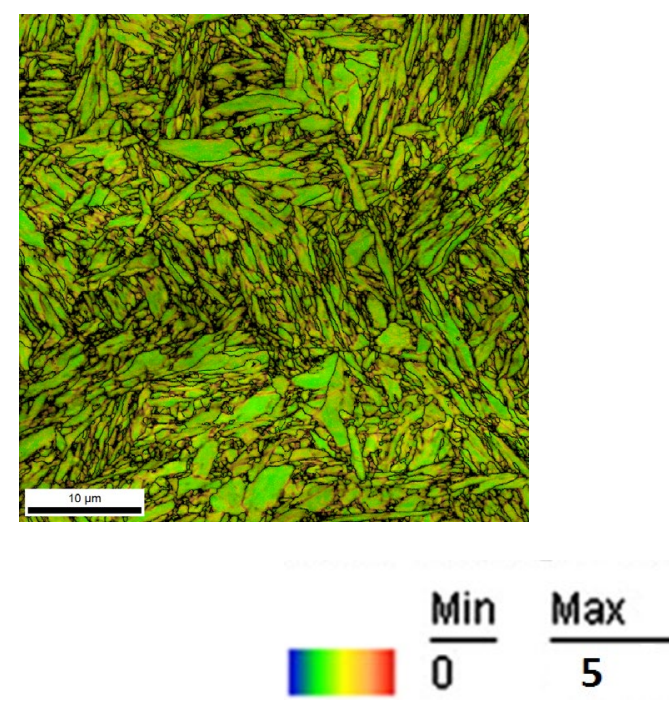

(d)

Figure 8. EBSD Kernal Average Map (KAM) of medium-carbon low-alloy steel deformed by double hit hot deformation at (a) $1200{ }^{\circ} \mathrm{C}-0.25 \mathrm{~s}^{-1}-5 \mathrm{~s}$, (b) $1200{ }^{\circ} \mathrm{C}-0.5 \mathrm{~s}^{-1}-5 \mathrm{~s}$, (c) $1150{ }^{\circ} \mathrm{C}$ $0.25 \mathrm{~s}^{-1}-5 \mathrm{~s}$ and (d) $1150{ }^{\circ} \mathrm{C}-0.5 \mathrm{~s}^{-1}-5 \mathrm{~s}$. Black lines denote HAGB. 


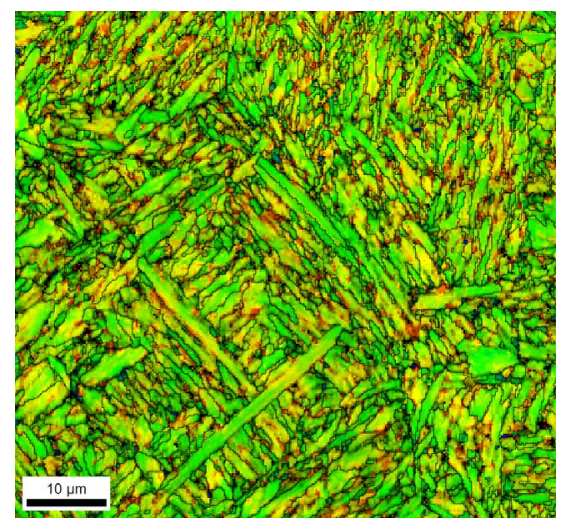

(a)

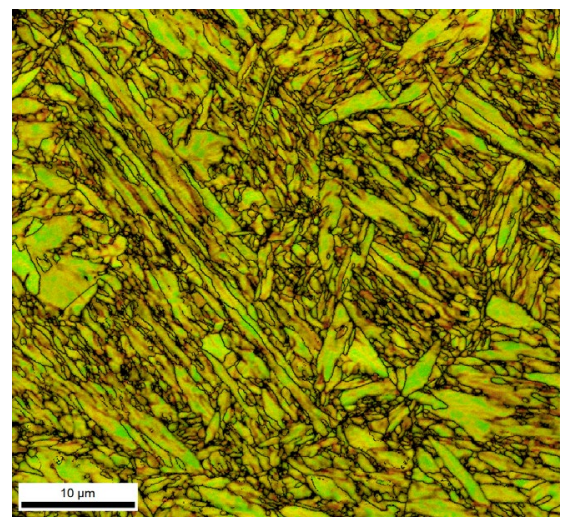

(c)

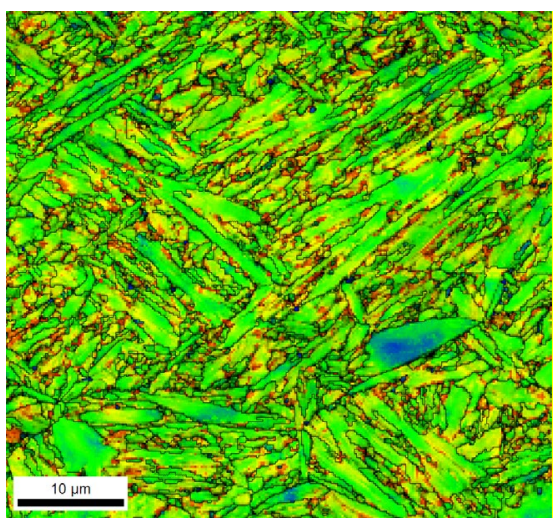

(b)

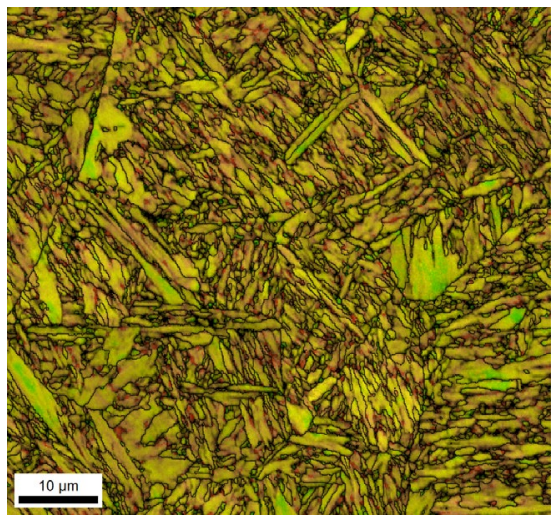

$\frac{\operatorname{Min}}{0} \frac{\operatorname{Max}}{5}$

(d)

Figure 9. EBSD Kernal Average Map (KAM) of medium-carbon low-alloy steel deformed by double hit hot deformation at (a) $1200{ }^{\circ} \mathrm{C}-0.25 \mathrm{~s}^{-1}-\mathbf{2 5 s}$, (b) $1200{ }^{\circ} \mathrm{C}-0.5 \mathrm{~s}^{-1}-25 \mathrm{~s}$, (c) $1150{ }^{\circ} \mathrm{C}$ $0.25 \mathrm{~s}^{-1} \mathbf{- 2 5 s}$ and (d) $1150{ }^{\circ} \mathrm{C}-0.5 \mathrm{~s}^{-1} \mathbf{- 2 5 s}$. Black lines denote HAGB. 


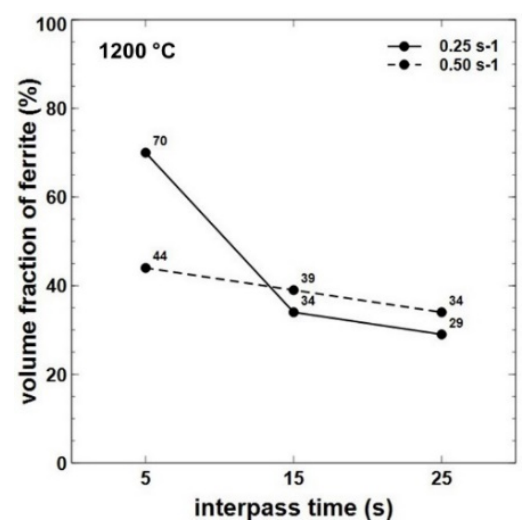

(a)

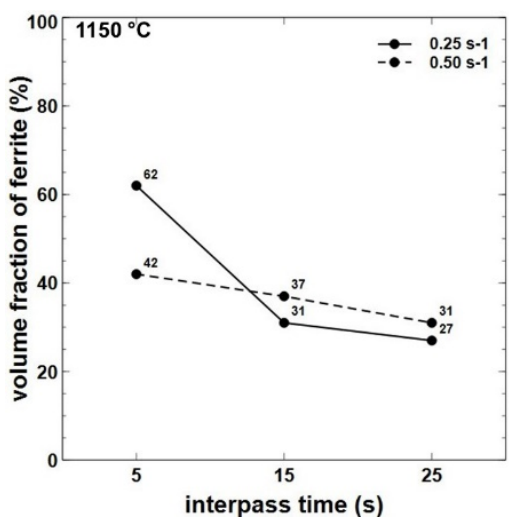

(b)

Figure 10. Graph of variation of ferrite fraction $\left(\mathrm{KAM}<2^{\circ}\right)$ vs. interpass time. The graph reveals the effect of interpass time on ferrite fraction.

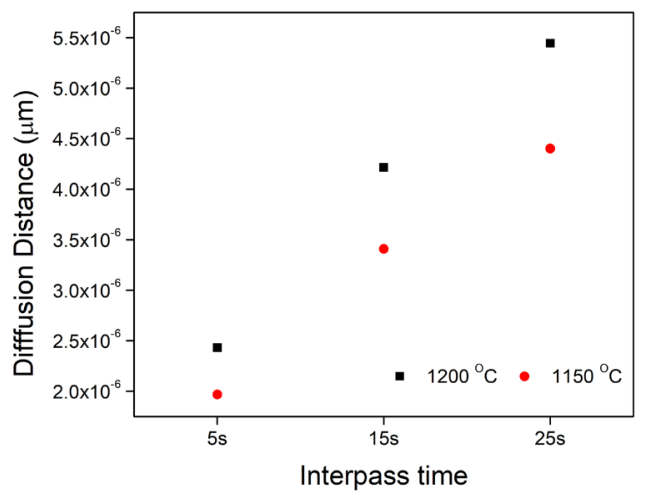

Figure 11. The variation of diffusion distance, $x(\mu \mathrm{m})$ due to lattice diffusion coefficient vs. interpass time. 


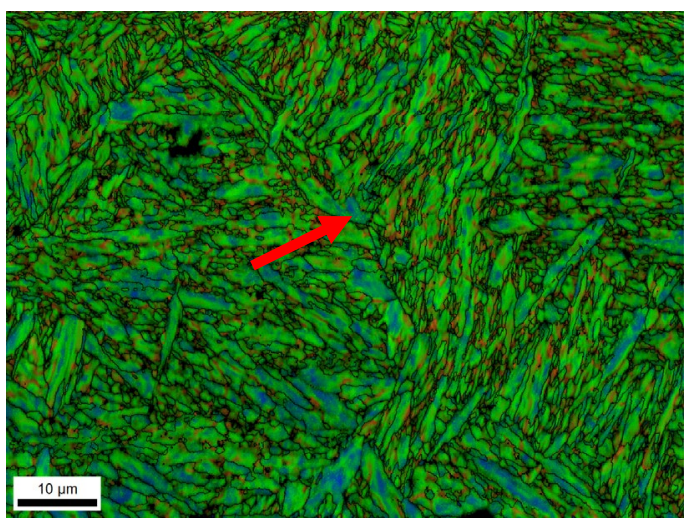

(a)

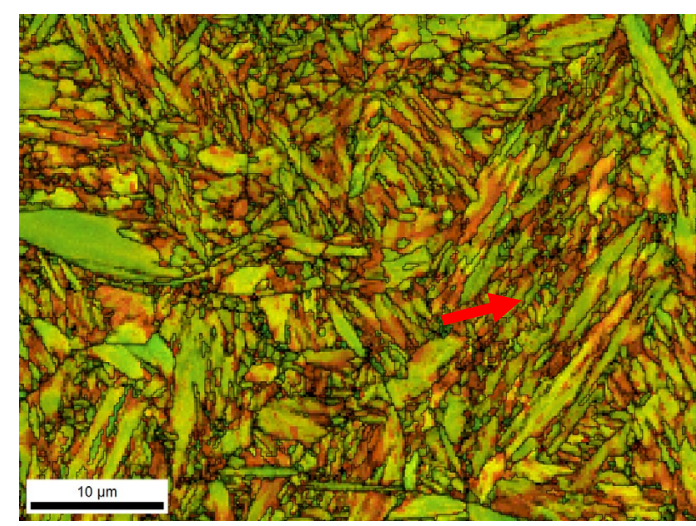

Min Max

(b)

Figure 12. EBSD Kernal Average Map (KAM) of medium-carbon low-alloy steel deformed by double hit hot deformation after break interpass time of (a) $5 \mathrm{~s}$ and (b) $25 \mathrm{~s}$. Black lines denote HAGB

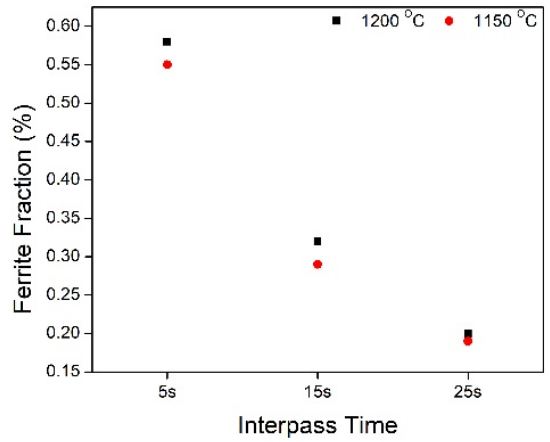

Figure 13. Graph of variation of ferrite fraction $\left(\mathrm{KAM}<2^{\circ}\right)$ vs. break interpass time. The graph reveals the effect of interpass time on ferrite fraction at strain rate of $0.25 \mathrm{~s}^{-1}$. 


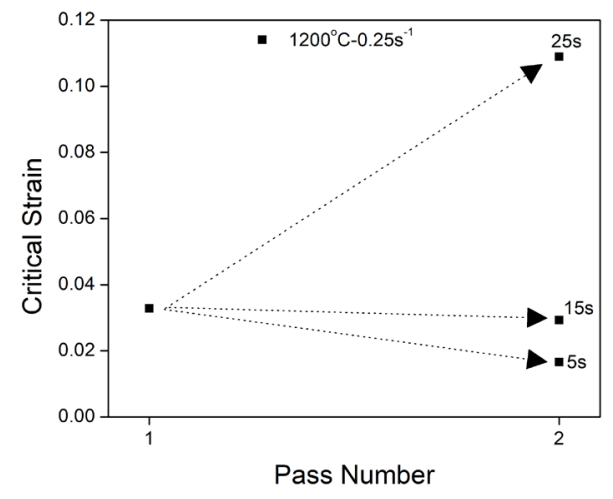

(a)

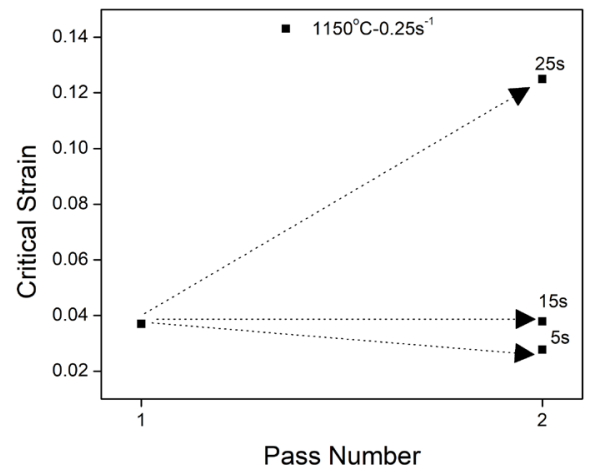

(c)

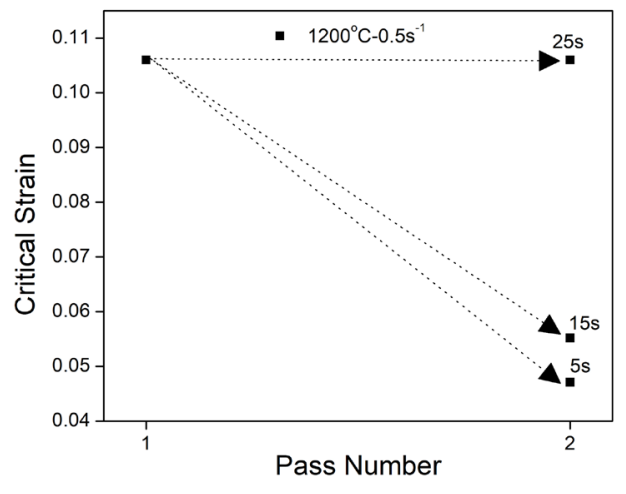

(b)

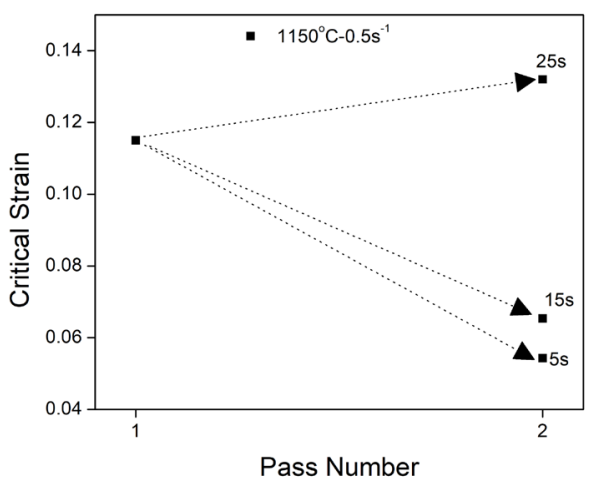

(d)

Figure 14. Variation of critical strain vs. pass number i.e. first hit ( $1^{\text {st }}$ pass $)$ and second hit ( $2^{\text {nd }}$ pass).
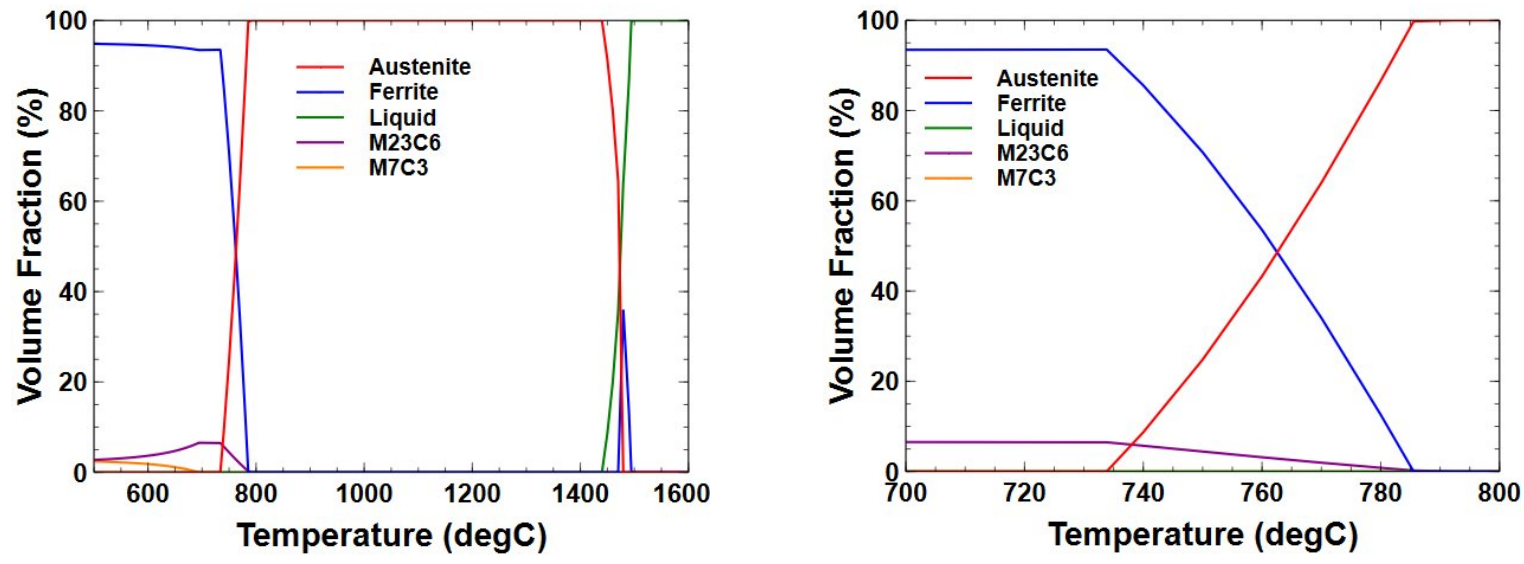

(a)

(b) 
Figure 15. (a) Dependence of equilibrium phase fraction w.r.t temperature and (b) region of start of austenite and ferrite phase

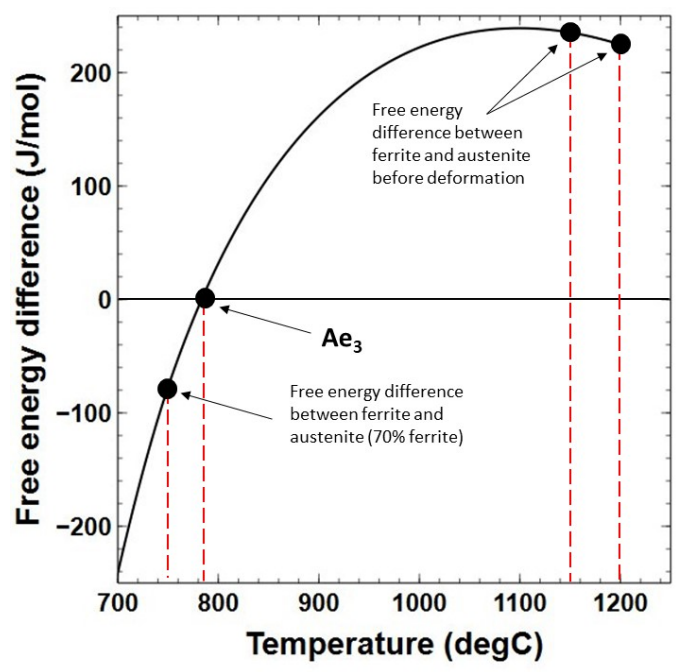

Figure 16. The difference between the free energy of austenite at deformation temperature and at $750{ }^{\circ} \mathrm{C}$ is the driving force applied to austenite to initiate the phase transformation. 